\title{
POPRAVLJANJE IN ODPRAVLJANJE NAPAK V PROCESU USVAJANJA TUJEGA JEZIKA
}

Tako kot pri procesu usvajanja maternega jezika, se tudi pri usvajanju tujega jezika neizogibno pojavljajo napake. Le-te so sestavni del učenja na poti do končnega cilja - komuniciranja v tujem jeziku, ki se približuje komuniciranju maternih govorcev, predvsem obvladovanju specifičnih struktur in besedišča ciljnega jezika. V našem sestavku bomo najprej osvetlili pojem napake, ki nastane pri procesu usvajanja tujega jezika in vlogo jezikovne norme pri prepoznavanju napak in opredeljevanju do le-teh, nato pa se bomo posvetili učiteljevi in učenčevi vlogi pri ugotavljanju in odpravljanju napak ter predstavili nekaj smernic za postopno zmanjševanje količine napak pri učencih.

\section{KAJ JE NAPAKA}

V šestdesetih letih 20. stoletja je preučevanje usvajanja tujega jezika P. Corderja, kasneje pa tudi R. Porquiera (Porquier, 1995) ter C. Jamesa (James, 1998) privedlo do razločevanja med »error «, ki je posledica nepoznavanja ustrezne strukture ali pravila v L2 in »mistake «, ki je posledica neustrezne uporabe nekega pravila (Corder, 1982). Error je tako s stališča teorij jezikovnega usvajanja napaka kompetence (jezikovnega znanja), mistake pa napaka performance (dejanjske uporabe jezikovnega znanja) oziroma konkretne manifestacije kompetence.

$\mathrm{V}$ skladu z zgornjimi trditvami so razlike med error in mistake v sledečem:

\begin{tabular}{|l|l|}
\hline $\begin{array}{l}\text { ERROR = ERREUR DE COMPETENCE = } \\
\text { NAPAKA NA RAVNI ZNANJA (NAPAKA KOMPETENCE) }\end{array}$ & $\begin{array}{l}\text { MISTAKE = ERREUR DE PERFORMANCE = } \\
\text { NAPAKA V RABI (NAPAKA PERFORMANCE) }\end{array}$ \\
\hline $\begin{array}{l}\text { Se ponavlja } \\
\text { (je sistematična). }\end{array}$ & $\begin{array}{l}\text { Se ne ponavlja } \\
\text { (je nesistematična). }\end{array}$ \\
\hline $\begin{array}{l}\text { Učenec je ni sposoben popraviti sam (potrebno je } \\
\text { dodatno učenje). }\end{array}$ & $\begin{array}{l}\text { Učenec jo lahko popravi sam, če se ga na } \\
\text { napako opozori. }\end{array}$ \\
\hline $\begin{array}{l}\text { Je posledica pomanjkanja ali ne dovolj razvite jezi- } \\
\text { kovne zmožnosti. }\end{array}$ & Ne potrebuje posebne obravnave. \\
\hline
\end{tabular}

V francoščini ima beseda napaka dve ustreznici: »faute« in »erreur«. Prva ima slabšalno, moralno konotacijo, pojem erreur pa je manj kulturološko zaznamovan in bolj nevtralen. Pedagogi, ki danes želijo na novo opredeliti vlogo in položaj besede erreur v procesu usvajanja tujega jezika, so temu izrazu bolj naklonjeni. Bolj 
kot pojem faute, erreur napeljuje k razmišljanju o vzrokih in oblikah odmikov od norme (Calvet 1988: 23).

Danes v frankofonskem okolju oba izraza še vedno sobivata. Sčasoma se je obema izrazoma pridružila še plejada sopomenk kot so »les écarts«, »les déviances«, »les prestations incorrectes«, »les imperfections«, »les incorrections« ipd., pri čemer gre za neke vrste intelektualističnih evfemizmov.

V slovenščini je nenapisana praksa pedagoških delavcev taka, da izrazi »nepravilna/napačna/odklonska oblika« označujejo napake, ki kažejo odklon od jezikovnega sistema, medtem ko izraz »neustrezna/nesprejemljiva rešitev « označuje napake, ki kršijo uveljavljeno naravno rabo. Pri tem v jezikovni sistem (Riegel et al. 2002: 604) uvrščamo vse paradigme in strukture danega jezika ter pri napakah ugotavljamo slovnično ustreznost in skladnost $\mathrm{z}$ jezikovnimi pravili.

Tretji tip napak so lapsusi oziroma spodrsljaji (fr. lapsus, ang. slip), ki ponavadi nastanejo zaradi trenutne raztresenosti učenca in jih le-ta največkrat zlahka odkrije in popravi sam, brez pomoči profesorja. Corder jih je uvrstil med takoimenovane posistemske napake (ang. postsystematic errors), pri katerih učenec pravilo sicer pozna, vendar ga včasih ustrezno, spet drugič pa neustrezno uporabi (Corder 1982).

Nazadnje omenimo še pojem »prikrite napake«, pri kateri oblika na videz ne odstopa od norme oziroma je besedilo na površini pravilno oblikovano, vendar ni v skladu s sporazumevalnim namenom (James, 1998: 68). Da bi tako napako lahko prepoznali, je treba poznati sporočevalčevo namero oziroma raziskati sobesedilo. Tovrstne napake nekateri jezikoslovci imenujejo »globalne«, saj za razliko od »lokalnih«, ki že na prvi pogled kažejo svojo odklonskost, »globalne« prizadenejo bistveno večji del besedila (Pirih-Svetina 2003:21).

\section{NAPAKA V ODNOSU DO NORME}

Napake največkrat označujemo kot odmike od norme. Čeprav je učitelj, sicer poklicno nujno zavezan knjižnojezikovni normi, vseeno »učencem predstavlja enkrat tako, drugič drugačno rabo med tistimi, ki jih je odkrilo uporabno jezikoslovje» (Calvet, 1988: 23). Toda vsaka od teh različic lahko v določenih okoliščinah sama predstavlja normo, kar pomeni, da norma ni ena sama, temveč da je norm lahko več.

Toda pojem norme je potrebno še natančneje opredeliti, saj si učitelj v zvezi s produkcijami učencev neprestano zastavlja vprašanja kot so: »Ali je ta izrek razumljiv?«; »Ali ga je mogoče ustrezno interpretirati?«;»Ali je slovnično pravilen?« Seveda odgovori na ta vprašanja niso vedno enostavni.

\subsection{Merila za odklon od jezikovne norme in jezikovnega sistema}

Marina Yaguello (1991) in Claude Gruaz (1995) opozarjata na nujnost razlikovanja med jezikovnim sistemom na eni in normo na drugi strani. Pri tem se pojma »odklon « in »obrobnost « nanašata na normo, pojma »paradigma « in »struktura" pa na jezikovni sistem. 
Če na primer voznik taksija v prometni gneči v Parizu reče: »Ça voiture sec aujourd'hui! « in doda »Il pleut des voitures, quoi!« sta to seveda obrobna, marginalna izreka. Kljub temu ju lahko umestimo v paradigmo neosebnih struktur, kar pomeni, da sta, tudi če ju občutimo kot odklonska, kljub vsemu to dva izreka, ki se umeščata med obstoječe strukture danega jezika. Nasprotno pa sta izreka kot »* Je le te prends. « in »*Je me viens. «v neskladju z jezikovnim sistemom in ju rojeni govorci verjetno ne bi oblikovali. Tovrstne napake so seveda mnogo bolj pogoste pri učencih tujega jezka, pri katerih tudi sicer lahko pričakujemo veliko večjo paleto raznovrstnih napak. Sicer pa »zmožnost oblikovanja »deviantnih« (odklonskih) izrekov ravno tako kot zmožnost oblikovanja »gramatičnih « (slovnično ustreznih) izrekov izhajata iz posameznikove jezikovne zmožnosti« (Yaguello 1991: 9).

Opozoriti moramo še na interakcijo med jezikovno rabo in jezikovnim sistemom. Vsak jezik na eni strani zaznamuje rigidnost kodiranja in na drugi ohlapnost ter prilagodljivost rabe (npr. raba subjunktiva za veznikom après que). Vse potencialne možnosti jezikovnega sistema se tudi ne odražajo v rabi, kar pomeni, da avtomatičnega prenosa pravil tega sistema ni. Tako se učencu tujega jezika lahko na primer zdi, da se predpona »in« uporablja zelo nepredvidljivo. Ce iz pridevnika »attaquable« tvorimo »inattaquable« in iz »gérable« $\rightarrow$ »ingérable«, pa za pridevnik »aimable« ne najdemo oblike » ${ }^{*}$ inaimable«. S to vrsto težav se srečujejo tudi rojeni govorci, saj oboji skušajo pravila jezikovnega sistema uporabljati tudi izven področja njihove rabe.

V skladu s trditvijo, da je napaka odklon od jezikovnih norm na eni in od jezikovnega sistema na drugi strani (Debyser et al. 1970; Ellis 1994), N. Pirih Svetina (2003: 21) navaja merila, ki te odklone opredeljujejo:

$>$ gramatičnost $t^{1}$ oziroma negramatičnost, pri čemer so negramatične vse tiste oblike, ki v določenem jezikovnem sistemu in v njegovih paradigmah sploh ne obstajajo. Gramatičnost tudi ni odvisna od konteksta, saj v resnici ne obstaja noben kontekst, v katerem bi bila ta oblika sprejemljiva kot v primeru *je prens, *je veux que je parte.

sprejemljivost oziroma nesprejemljivost označuje $z$ vidika merila gramatičnosti pravilno poved, a je v neskladju z običajnimi sporazumevalnimi praksami. Med razlogi, da nek izrek označimo za nesprejemljiv, so na primer prekomerna dolžina, kompleksnost ali nejasnost tega izreka.

Poved L'élève dont le devoir que j'ai lu hier soir était mauvais est votre fils. je tvorjena slovnično pravilno. To lahko ponazorimo z oglatimi oklepaji : [L'élève[dont le devoir]que j'ai lu hier soir] était mauvais] est votre fils.] Sorazmerno kompleksna struktura te povedi (vsebuje oziralni odvisnik, ki je del drugega oziralnega odvisnika, ta pa je spet vrinjen v stavek $L$ 'élève est votre fils.) bi bila sprejemljiva kvečjemu pri ustni izmenjavi dveh govorcev. Sicer bi bilo potrebno odstraniti en oziralni odvisnik in poved ne bi bila več problematična : L'élève dont le devoir [...] était mauvais est votre fils.

1 Pojem gramatičnost $\mathrm{v}$ širšem pomenu označuje skladnost nekega izreka $\mathrm{z}$ oblikoslovnimi, skladenjskimi, semantičnimi pa tudi pragmatičnimi pravili danega jezika (Riegel et al. 2002: 20). 
Merilo sprejemljivosti je odvisno od konteksta, avtoriteta za presojanje ustreznosti oziroma neustreznosti pa je naslovnik. Ta kot sprejemljiv označi tisti izrek, ki ga brez težav interpretira v kateremkoli kontekstu. Kot sprejemljivo lahko torej označi neko različico knjižnega jezika. Različice so lahko :

a) leksikalne narave; n.pr. »barrer la porte«, ki je v nekaterih francoskih pokrajinah pogosto rabljen izraz in enakovreden izrazu »fermer la porte«.

b) skladenjske narave; n.pr.: »Tu viens ce soir? « in »Est-ce que tu viens ce soir?«

c) redko tudi slovnične narave; n.pr.: »Le groupe de touristes qui m'a demandé...« ali »qui m'ont demandé...«.

K tem različicam lahko prištejemo še druge, bolj številne, ki jih ponavadi uvrščamo med funkcijske značilnosti jezika in so povezane s sporazumevalnim položajem. Res je, da so te različice bolj prisotne, pa tudi bolj tolerirane v govorjenem besedilu kot v zapisanem.

pravilnost oziroma nepravilnost (fr. correct/incorrect), ki se nanaša na oblike, ki same po sebi ne ostopajo od norme, vendar napačne postanejo v okviru večjih jezikovnih enot ali v sobesedilu, v katerem se pojavijo kot v primerih: *aller au docteur ali *il est dessous la conette.

tujost kot »pesniška svoboda«v kontekstu rojenih govorcev (npr. Paul Eluard: »La terre est bleue comme une orange«.) in neumestnost (fr. la non-adéquation, la non-pertinence), ki je stvar kršenja pragmatičnih pravil. Na vprašanje »Viens-tu dîner à la maison, ce soir? « pričakujemo potrdilo ali zanikanje, ki je lahko pospremljeno $\mathrm{z}$ argumenti, nikakor pa ne odgovora: »Cette robe, elle a l'ourlet qui est décousu«. Tak odgovor lahko upraviči le ustrezen kontekst (npr. oseba, ki ravnokar šiva), s pomočjo katerega sogovornik odgovor interpretira takole: »Je ne peux pas venir car je dois terminer ce que j'ai commencé«.

Pri pouku tujega jezika se učitelju seveda zastavlja vprašanje, katere norme in merila naj upošteva pri obravnavanju napak. Na nižjih ravneh poučevanja tujega jezika bi bilo verjetno povsem sprejemljivo, če bi učitelj, v skladu z učenčevo nižjo jezikovno zmožnostjo, večji poudarek namenil preskriptivnim normam in odklonom od jezikovnega sistema, saj imajo na tem področju učenci tudi največ težav. Kasneje, ko učenci že bolj obvladajo tuji jezik, pa bi pri obravnavi napak seveda lahko v večji meri upošteval tudi vsa ostala merila in norme.

\section{POPRAVLJANJE IN ODPRAVLJANJE NAPAK}

Kot končni cilj pouka tujega jezika v literaturi navadno zasledimo kompetenco rojenega govorca, čeprav vemo, da kompetenca rojenega govorca ni nujno dobro zastavljen cilj učenja - kompetenca vseh naravnih govorcev na primer ne dosega ravni C2 po evropskem okviru za jezike. Poleg tega velja opozoriti še na dejstvo, da se normi rojenega govorca lahko približamo po (strogo) jezikovni plati, veliko težje pa zadostimo vsem drugim kriterijem: poznavanje idiomov, aluzij - kulturnih, civilizacijskih in drugih, itd..

$\mathrm{V}$ preteklosti so imele različne jezikoslovne teorije in metode, ki iz njih izhajajo, na popravljanje napak zelo različne poglede: od prepričanja, da so napake 
nedopustne in jih je potrebno popraviti takoj, ko se pojavijo, ali pa še bolje, preprečiti, da bi se pojavile (behaviorizem), do popolne tolerance, ko učitelj napak ne popravlja in jim ne namenja posebne pozornosti (novejši pristopi, kot je t.i. »naravni pristop«(ang. the natural approach), ki sta ga v Ameriki leta 1983 razvila Terrell in Krashen.

Verjetno bi bilo najbolje, da oba ekstrema pustimo ob strani in se opremo na razmišljanja velikega števila jezikoslovcev, ki menijo, da bi morali imeti učitelji do napak strpen odnos, saj nobeno učenje $\mathrm{v}$ resnici ne poteka popolnoma brez napak. Poleg tega napak ne moremo kar ignorirati, saj so dragocen pokazatelj učenčeve trenutne zmožnosti v tujem jeziku. Trdimo lahko, da se ta zmožnost izboljšuje le, če učenec dobi povratno informacijo o tem, ali je tisto, kar je napisal, pravilno in sprejemljivo ali ne. Najprej bomo poskušali razložiti, kako se na napake učencev odziva učitelj, nato pa bomo predstavili še problem odpravljanja napak $z$ učenčeve perspektive.

\subsection{Vloga učitelja pri popravljanju in odpravljanju napak}

Učitelj se v odnosu do učenčevih napak seveda ne more zadovoljiti le z vlogo pasivnega opazovalca, temveč se nanje odziva $z$ namenom, da bi v čim večji možni meri omejil njihovo pojavljanje. Calvé (1992) trdi, da sta prepoznavanje in obravnava napak večinoma odvisna od presoje učitelja o realnih zmožnostih posameznega učenca v primerjavi z zmožnostmi rojenega govorca kot vzoru, h kateremu težijo. Pri tem se moramo zavedati, da imajo tudi nekateri rojeni govorci pomanjkljivo jezikovno zmožnost ter da ravno tako kot tujejezični govorci delajo napake.

Pri obravnavanju napak moramo upoštevati, s kakšnim namenom tuji jezik poučujemo ter zakaj, na kakšen način in v kakšnih okoliščinah bodo učenci ta jezik uporabljali. Pri učencu francoščine, ki se jezika uči, ker bo nekoč opravljal poklic receptorja v hotelu, bomo tako strožji v odnosu do določenega tipa napak (napake v govorjenem jeziku; napake, vezane na sporazumevalni položaj), medtem ko bomo druge tipe včasih spregledali. Nasprotno pa bomo na primer pri študentih francoščine do vseh tipov napak bistveno bolj nepopustljivi.

Popravljanje in odpravljanje napak je z didaktičnega vidika precej zapleteno področje, saj mora učitelj upoštevati številne dejavnike, kadar se odloča, če je napake učencev sploh potrebno popravljati; kdaj je najustreznejši trenutek, da jih popravi in ne nazadnje na kakšen način naj jih popravi.

Postopek razvijanja metajezikovnega znanja, s katerim bi učence pripravili do tega, da bi razumeli svoje napake in jih omejili na minimum, je opisal že A. Lamy (1997: 124-125), ki predlaga sledeči vrstni red:

1) Preučitev deviantne strukture; učenci to lahko opravijo sami ali pa s pomočjo učitelja.

2) Prvi poskus poprave opravijo učenci.

3) (Fakultativno) primerjava $z$ maternim jezikom.

4) Preoblikovanje, kjer je napačni element pravilno uporabljen (pri preoblikovanju si pomagamo s štirimi osnovnimi operacijami: dodajanje, odvzemanje, premeščanje in zamenjava). 
5) Izdelava primerjalne tabele ( $z$ nepravilno in popravljeno obliko), da poudarimo razliko med obema oblikama.

6) (Fakultativno) od učencev zahtevamo, da s pomočjo opazovanj poskušajo razložiti obravnavani jezikovni mikrosistem.

7) Zbiranje podobnih struktur kot je tista, ki so jo učenci predlagali v točki 2 (popravljena formulacija).

8) Učenci tvorijo stavke po predlaganih zgledih.

\subsection{Presojanje o potrebnosti popravljanja napak}

Ker danes zagovarjamo spontano izražanje pri učencih, vseh napak, ki se pri ustnem in pisnem sporočanju pojavijo, niti ni mogoče popravljati. Popravljanje napak lahko včasih res ovira komunikacijo in nespodbudno deluje na učence. Vendar pa kljub temu velja popravljati napake, ki znatno ovirajo komunikacijo, in tiste, ki učencu onemogočajo uspešno nadaljevanje učenja, ter napake, ki se zelo pogosto ponavljajo. Učitelj je torej pri popravljanju napak prisiljen ravnati po principu izbire. Ta izbira je odvisna od številnih dejavnikov, med katerimi bomo omenili štiri:

a) Učitelj mora vedeti, do katere mere njegovi učenci že obvladajo tuji jezik, saj je od tega odvisna tudi njihova sposobnost odkrivanja in popravljanja napak. Calvé (1992) priporoča popravljanje napak, ki se pojavljajo redno in v različnih kontekstih. Pri takih napakah namreč obstaja nevarnost zakoreninjenja oziroma fosilizacije.

b) Učitelj mora pri popravljanju napak ravnati v skladu s cilji, ki si jih je zastavil pri učnem procesu. Če na primer učitelj učencu dopušča, da v tujem jeziku neovirano tvori izreke, $\mathrm{v}$ katerih so prisotne napake, obstaja tudi tu velika nevarnost, da se bodo te napake pri učencu zakoreninile. To pa lahko znatno upočasni napredovanje in usvajanje L2. Učitelju je verjetno najtežje najti pravo mero.

c) Učitelj mora upoštevati tudi število učencev pri pouku tujega jezika. Če je na primer skupina večja, učenci napake lahko učinkovito popravljajo v parih ali skupinah, pri manj številčnih skupinah pa se seveda učitelj lahko bolj posveti vsakemu posamezniku posebej.

d) Popravljanje in odpravljanje napak je odvisno tudi od potreb učencev pri usvajanju L2. Će na primer izobražujemo bodoče učitelje tujega jezika, moramo biti pri popravljanju seveda bolj dosledni kot če tuji jezik na primer učimo bodoče natakarje.

Semke (1984: 24) opozarja na nekatere slabe plati neposrednega popravljanja napak. Tak način popravljanja namreč predpostavlja korekcijo vsake napake v dani pisni produkciji, najsi pripada pravopisni, jezikovni, vsebinski ali pa oblikovni ravni. V raziskavi, ki jo je naredil s študenti nemščine kot tujega jezika, se je izkazalo, da je množica napak, ki jih je odkril učitelj, študente demotivirala, saj so imeli občutek, da ne bodo nikoli premostili vseh težav pri pisanju. Poleg tega se je pokazalo, da táko, dosledno popravljanje vseh napak, dolgoročno nima želenega učinka pri zmanjševanju števila napak. Ker tak način popravljanja tudi od učitelja zahteva znaten napor in čas, bi se morda kazalo zateči k drugačnim metodam po- 
pravljanja, ki bi tudi učitelja manj obremenjevale. Morda tako, da bi se vsakokrat omejil le na določeno kategorijo napak.

\subsection{Izbira najugodnejšega trenutka za popravljanje napak}

Če se učitelj odloči, da bo napako popravil, to lahko stori takoj, ko napako odkrije (v ustnem sporočanju), lahko pa jo popravi tudi s krajšim ali daljšim časovnim zamikom.

\section{1) Takojšnje popravljanje}

Pri ustnem sporočanju ima učitelj za oceno situacije navadno na razpolago le nekaj trenutkov in četudi ima pri pedagoškem delu že veliko izkušenj, ne more vedno sprejeti tehtne odločitve o popravljanju napak. Avtomatičen in takojšen odziv na napako je radikalna rešitev, ki se je poslužujejo predvsem učitelji začetniki, odobravali pa so jo tudi na začetku 60. let 20. stoletja pod vplivom behavioristične teorije usvajanja tujega jezika. Vendar pa avtomatično, refleksno popravljanje navadno izključuje tehten razmislek o sami naravi napake, o njenih vzrokih, kar vnaša dvome o ustreznosti takega načina popravljanja. Če se namreč na vsak tip napake in pri vsakem učencu odzovemo enako, to pomeni, da nismo upoštevali individualnih razlik med učenci in je naše posredovanje lahko neučinkovito ali celo škodljivo. Kognitivni psihologi razlikujejo med štirimi tipi individualnih posebnosti: kognitivne razlike (kognitivni stil, učni stil, inteligenca in sposobnost učenja), čustvene razlike (motivacija, osebnost, strah in samozavest), družbene in kulturne razlike (starost, spol, predhodno izobraževanje) in uporaba učnih strategij. Pri tem slednje uvrščajo med zavedne razlike, vse ostale pa med nezavedne.

2) Popravljanje s krajšim časovnim zamikom učitelju nudi dovolj časa, da se odloči, kako bo posredoval pri napaki. Posreduje lahko učenec sam (samopopravljanje), drugi učenci, učitelj ali pa se te možnosti kombinirajo.

3) Popravljanje z daljšim časovnim zamikom učitelju nudi več časa za razmislek o tem, kako bo posredoval. Lahko se omeji na določen tip napake in se nato odloči za bolj razširjeno in poglobljeno obravnavo nekega jezikovnega pojava, za katerega se je izkazalo, da ga učenci slabše obvladajo.

\subsection{Način popravljanja napak}

Ažman (2004:17) opozarja na prednosti oblike usmerjenega pouka pri usvajanju L2, kjer učitelj učenčevo pozornost usmeri na določeno nepravilno obliko. Opozarjanje na nepravilnosti je lahko napovedano oz. proaktivno, ko učitelj usmeri učenčevo pozornost na nepravilno obliko, ali reaktivno, ko se učitelj odzove na učenčevo napako. Učitelj se lahko odzove:

$>Z$ eksplicitnim popravkom (to je ponavadi bežen, takojšen popravek napake $\mathrm{v}$ obliki zamenjave neustreznega $z$ ustreznim jezikovnim izrazom, ponavadi še med trajanjem učenčeve izjave).

S preoblikovanjem učenčevih oblik in vsebin.

> $\mathrm{Z}$ metalingvistično povratno informacijo (vprašanja $\mathrm{v}$ zvezi $\mathrm{z}$ napako).

$>\mathrm{Z}$ iskanjem pravilne oblike skupaj $\mathrm{z}$ učenci. 
Z omenjenimi ukrepi učitelj usmerja učenčevo pozornost na naravo napake in na njeno slovnično podlago ter eventualno od učencev pridobi razlago o vzrokih odklonske oblike. Učencem lahko na primer predlaga, da v popravljenih in vrnjenih pisnih izdelkih razvrstijo napake po posameznih kategorijah oz. da sami predlagajo tipologijo svojih napak. To od učencev sicer zahteva že solidno poznavanje slovnice, od učitelja pa nekoliko več dela, saj bi moral vsako predlagano tipologijo pregledati in pokomentirati z učenci. Taka vsakemu posamezniku prilagojena tipologija bi bila solidna osnova za podrobno analizo pomanjkljivosti $\mathrm{v}$ njegovih pisnih izdelkih in bi ga opozarjala na elemente, na katere mora biti $\mathrm{v}$ bodočih produkcijah še posebej pozoren.

Ko govorimo o načinu odpravljanja napak, se dotaknemo tudi področja korektur. Te bi morale biti pri pisnem izražanju jasne, natančne, dosledne, pravične in konstruktivne. Učitelj mora upravičenost svojih korektur podkrepiti tudi z doslednimi kriteriji, drugačnimi od tistih, ko nas zavede in rečemo: »Ta poved pa ne zveni francosko.« Na doslednost pri popravljanju in utemeljenost korektur je potrebno navaditi tudi učence. To lahko storimo s pomočjo vaje, ko na primer učencem ponudimo besedilo brez napak, v katerem podčrtamo posamezne strukture in od učencev zahtevamo, da utemeljijo njihovo rabo. Pri naslednjem koraku lahko podčrtamo nekaj pravilnih in nepravilnih struktur, pri čemer se vse nanašajo na neko specifično slovnično poglavje. Učenec bo moral najprej ugotoviti, katere strukture so napačne in nato utemeljiti svojo odločitev.

Pri vlogi učitelja pri popravljanju in odpravljanju napak velja omeniti tudi odnos med učiteljem in učenci. Učitelj bi si moral prizadevati, da bi z učenci vzpostavil odnos, ki temelji na pomoči, usmerjanju in spodbujanju (poudarjanje učenčevega napredka, ne napak) in ne na učiteljevi moči. Učenci namreč do marsikaterega učitelja še vedno občutijo nekakšno strahospoštovanje, ker v njihovih očeh predstavlja »neusahljiv« vir znanja in »nedosegljiv« vzor.

Učitelj bi moral neprestano razvijati samorefleksijo v tej smeri, da bi premislil, kaj lahko naredi bolje in drugače pri pouku v smeri preprečevanja, zmanjševanja in odpravljanja napak učencev.

\subsection{Vloga učenca pri popravljanju in odpravljanju napak}

Učenci imajo pri popravljanju in odpravljanju napak zelo pomembno vlogo. Za uspešno obvladovanje te vloge morajo biti dani vsaj štirje pogoji; učenec mora biti motiviran, da popravi svoje napake, biti mora informiran o storjeni napaki, seznaniti ga je potrebno s pravilno obliko in za odpravljanje napak mora imeti na voljo pestro izbiro ciljno usmerjenih vaj.

\subsubsection{Motiviranje učenca za popravljanje lastnih napak}

Učenec je sposoben sam popraviti le napake performance, torej tiste, pri katerih je pravila že usvojil, a jih iz različnih razlogov ni pravilno uporabil. Poleg tega mora imeti željo ali čutiti potrebo po odpravljanju svojih jezikovnih napak. Napake se načeloma da popraviti in odpraviti le, če učenec v tem vidi nek smisel in je za to dovolj motiviran ter sam uvidi, da je to potrebno. Če vemo, da učenje temelji na 
kognitivnih in razumskih procesih, je razumljivo, da moramo učenca navaditi na razmišljanje o njegovih napakah. Poprava, ki jo izvede samo učitelj, žal ni zagotovilo za izboljšanje učenčeve produktivne jezikovne kompetence, edina zares koristna poprava je tista, ki jo naredi tudi učenec, s tem njegov izdelek postane premet analize in razmišljanja o delovanju jezikovnega sistema.

Če vzamemo za primer izboljšanje koherence v pisnih izdelkih, je zelo dobrodošlo individualno, pa tudi skupinsko razmišljanje o tem, kako nepopolna koherenca otežuje razumevanje in povečuje nevarnosti nepravilne interpretacije takega besedila. Da bi izboljšali koherenco, je torej treba razmisliti o funkciji samega sporočila, o informacijah, ki jih pisec želi posredovati in o organizaciji diskurza. Učenec, ki piše v tujem jeziku, navadno že ima določeno besedilno zmožnost iz svojega maternega jezika, ki je spet zaznamovana s kulturnimi značilnostmi tega jezika. Učitelj mora to upoštevati in izhajati iz te učenčeve zmožnosti, da jo potem skupaj z učencem preoblikuje.

\subsubsection{Informiranje učenca o storjeni napaki}

Učenec mora biti seznanjen $z$ dejstvom, da je tisto, kar je ubesedil, napačno. Vedeti mora, da je naredil napako. Napredoval bo lahko le v primeru, da bo imel možnost, da rekonstruira napačno usvojeno pravilo, ki ga uporablja (npr. vsi samostalniki tvorijo množino na »s« ali vsi samostalniki ženskega spola se končajo na »e«).

Opozarjanje na napako naj bi bilo za učenca čim manj travmatično in stresno. Temu cilju se najbolj približa samopopravljanje ali kakršnokoli popravljanje, ki ga spodbudi učenec sam. Raziskave kažejo, da so učenci sposobni popraviti sami kar do 20\% svojih jezikovnih napak (Bartram in Walton 1994: 74). Tudi popravljanje $\mathrm{v}$ pisnih produkcijah je za učence manj stresno kot ustno popravljanje pri ustnem sporočanju.

Učencu bolj naklonjena je tudi formativno preverjanje (za razliko od sumativnega), ki učence obravnava individualno in jih ne razvršča. Njena naloga je nuditi učitelju in učencu sprotno informacijo o učenčevem znanju. Učitelj z njeno pomočjo dijake opozarja na njihove težave in jim lahko nudi takojšnjo pomoč (Lah 2001:55).

Učitelj se lahko odloči, da označi le vrstico, v kateri je našel eno ali več napak, namesto da napako, kot običajno, popravi. S tem učenca spodbudi, da se potrudi in napako poišče, česar mu pri običajnem popravljanju ni treba storiti, ker je to namesto njega opravil učitelj. Še manj pomoči pa bi učenec dobil, če bi učitelj navedel le skupno število napak, ki jih vsebuje posamezna poved, odstavek ali pa kar celotno besedilo, če je napak malo. S tem bi učence navajal na (samo)prepoznavanje napak in na pregledovanje lastnih besedil.

Seveda pa učenec ni vedno sposoben sam odkriti svoje napake. To lahko onemogočijo tudi okoliščine, $v$ katerih je do napake prišlo. $V$ takem primeru na napako lahko opozori učitelj (na primer z gestami ali obrazno mimiko) ali drugi učenci. Učitelj ima prav tako možnost, predvsem v primeru nareka (redko v ustni produkciji), da z zgoraj omenjenimi tehnikami učenca vnaprej opozori, da mu preti napačna raba. Gre za tako imenovano metodo »odprtih kart« oz. na navajanje na vklop »kontrolnega alarma«. 
Če napake popravljajo drugi učenci, jim je pri tem v pomoč distanca, ki jo imajo drugi učenci do besedila, $v$ katerem so prisotne napake. Prav tako popravljanje produkcij drugih učencev lahko ugodno vpliva na samozavest tistega, ki popravlja, saj ima občutek, da je sam v pisnem sporočanju že napredoval. Sčasoma se poveča tudi zmožnost kritične analize lastnih produkcij, kar je osnova za izboljšanje pisne zmožnosti (Sokolov 2000: 493).

Primeri napak, ki jih učenec sam pa tudi drugi učenci ponavadi ne morejo popraviti, so težave, povezane $z$ globalno besedilno oz. diskurzivno zgradbo kot je raba utemeljevalnih povezovalcev v utemeljevalnem tipu besedil ali pa raba časovnih prislovov in veznikov ter glagolskih časov v pripovednem tipu besedil.

\subsubsection{Informiranje učenca o pravilni obliki}

Če smo učencu pomagali, da je napako odkril sam, smo s tem rešili le del težav. Naslednji korak je pomoč pri popravljanju napak. Učenec mora (iz)vedeti, kakšna je pravilna oblika in kako se pravilno uporablja.

Ena od možnih poti do seznanjanja učenca s pravilnimi oblikami je preoblikovanje (Levenston 1978; Johnson 1988), ki se lahko uporablja na različne načine. Temeljni postopek je preoblikovanje izvirnega učenčevega besedila, ki jo opravi rojeni govorec. Ta napiše različico celotnega besedila tako, da v največji možni meri ohrani njegov prvotni smisel.

Preoblikovanje (Johnson 1988: 91) se razlikuje od rekonstrukcije, kjer učitelj samo popravi učenčeve napake, kar v praksi učitelji navadno tudi počnemo. Učenci, ki bi besedila preoblikovali sami, bi lahko prišli do povedi, v katerih ne bi bilo večjih nepravilnosti, pa tudi do takšnih, ki bi bile slovnično sicer pravilne, vendar jih za sporočanje iste vsebine rojeni govorec ne bi nikdar oblikoval. Pri preoblikovanju rojeni govorec torej $v$ nasprotju $\mathrm{z}$ rekonstrukcijo učencu ponudi tudi model pravilne rabe, kar je še posebej koristno pri pisnem sporočanju.

Žal se še vse prevečkrat dogaja, da učiteljevo signaliziranje napak ostane brez odziva na strani učencev. Čeprav pri učencih lahko opazimo precejšnjo nestrpnost in zanimanje za vrnjene popravljene pisne izdelke, pa si žal učenci popravljeno besedilo velikokrat pregledajo zelo bežno in zato od poprave ne potegnejo takih koristi kot bi jih, če bi popravljeno besedilo prepisali in analizirali popravljene formulacije. K večji preglednosti in boljšemu vpogledu v raznovrstne napake pripomore na primer razvrščanje napak $v$ kategorije. Učenec lahko tako svoje napake vpisuje $\mathrm{v}$ vnaprej pripravljene tabele, kjer je tipe napak po posvetu $\mathrm{z}$ učiteljem razvrstil po kategorijah, na primer $v$ kategorijo pravopisnih napak lahko vpiše nepravilno rabo naglasnih znamenj, $\mathrm{v}$ kategorijo skladnje $\mathrm{z}$ oblikoslovjem sodijo nepravilnosti pri glagolskih oblikah, samostalniku, pridevniku, zaimku,..., na skladenjsko-besedilni ravni si lahko vpiše napake, ki zadevajo nepravilni vrstni red, pa nepravilno rabljene glagolske čase, pa napake $\mathrm{v}$ rabi pridevnika, priporočljiva bi bila tudi kategorija, ki bi zajemala napake povezane $z$ neustrezno rabo besedišča, še zlasti glede na dejstvo, da pojavnost teh napak pri učencih tujega jezika sploh ni nezanemarljiva.

Pri vaji iz nareka pa bi bilo na primer koristno, če bi učenci sami poiskali napake, učitelj pa bi besedila še dodatno pregledal, saj iz prakse vemo, da tudi 
boljši učenci nekatere napake spregledajo. V zvezi s tem je še posebej priporočljivo t.i. »navzkrižno« popravljanje, ko učenci v parih ali manjših skupinah zamenjajo besedila in jih popravljajo. Moderne tehnologije nam danes omogočajo tudi skupinsko popravljanje posameznega pisnega izdelka, pri čemer je treba paziti, da avtor izdelka ostane anonimen. Tako lahko napisan narek učenci najprej pregledajo in pokomentirajo znotraj manjše skupine (3 ali 4 učenci), po uskladitvi mnenj ga po potrebi še popravijo. Pregledano in popravljeno besedilo vsake skupine potem učitelj projicira na projektorju in skupaj z ostalimi učenci pokomentira eventualne napake. Na tak način ni nihče od učencev poimensko izpostavljen, boljši pa s komentarji in razlagami pomagajo šibkejšim.

\subsection{Pomen vaje pri odpravljanju napak}

Učenje slovničnih pravil in značilnosti posameznih besedil je sicer nujno potrebno, vendar samo po sebi še ne zadostuje za odpravo napak in popolno obvladanje jezika. Zato je potrebno učenje nujno podkrepiti s praktičnimi vajami. Učenec mora torej imeti možnost, da vadi in popravi nepravilnosti. Koraka poprave napake in vaj za odpravljanje napak sta ključna za odpravljanje napak.

Prepričanje, da bo eno samo posredovanje učitelja zadostovalo za odpravo napake, je preveč optimistično. Podobno tudi en sam tip vaje za odpravo določene napake še ne naredi čudeža in je za to potrebna pravilna kombinacija različnih vaj.

$\mathrm{V}$ vajah za utrjevanje in urjenje, ki jih uporabljamo za odpravljanje napak (npr. ponavljalne slovnice) naj bi se učenci v njim prilagojenih odmerkih seznanjali tudi z novimi slovničnimi strukturami. Na ta način bi bogatili in dopolnjevali svoja izrazna sredstva in posledično izboljševali svojo jezikovno kompetenco.

Tudi preučevanje avtentičnih besedil učencem pomaga ponotranjiti modele, ki jih uporabljajo predvsem pri pisni produkciji. S preučevanjem in analizo podobnih besedil kot je tisto, ki naj bi ga učenci oblikovali, si učenci pridobijo repertoar diskurzivnih, besedilnih, stavčnih in leksikalnih oblik, ki jih bodo lahko s pridom uporabljali pri produciranju svojih lastnih besedil. Učitelj na tak način učence navaja tudi k razmišljanju o delovanju jezika in odnose med funkcijskimi značilnostmi besedil. Tako bi na primer v pojasnjevalnem tipu besedila, v katerem avtor predstavi vzroke nekega pojava, preučevali povezovalce (parce que, en raison de, ipd.) in leksikalne elemente (être dû à, être induit par, résulter de, ipd). $S$ poudarjanjem teh elementov bi učenci izboljšali tudi besedilno strukturo svojih produkcij.

Bisaillon (1992) meni, da je težave pri pisni produkciji težko rešiti z zatekanjem k vedno večjemu številu slovničnih vaj, ker poznavanje slovničnih pravil še ne pomeni tudi pravilne uporabe teh istih pravil v prosti produkciji. Ta se namreč precej razlikuje od strukturalnega tipa vaj.

\section{ZAKLJUČEK}

Članek skuša opozoriti na pomembnost popravljanja in odpravljanja napak $\mathrm{v}$ procesu usvajanja tujega jezika ter na aktivni vlogi, ki ju pri tem igrata tako 
učitelj kot učenec. Za lažjo obravnavo smo napake najprej opredelili v odnosu do jezikovne norme in predstavili različne tipe napak, ki jih srečamo v produkcijah učencev. Zavedati se moramo, da so napake dragocen pokazatelj učenčeve trenutne jezikovne zmožnosti in da se le-ta lahko izboljša le v primeru, da učenec dobi povratno informacijo o tem, ali je tisto, kar je proizvedel, pravilno in sprejemljivo ali ne. Pri različnih možnostih popravljanja in odpravljanja napak moramo upoštevati številne dejavnike (čas, motivacija,..), ki prispevajo k uspešni realizaciji zadanega cilja. Eden od teh je gotovo tudi navajanje učencev na refleksijo o delovanju jezikovnega sistema jezika, ki ga usvajajo ter razmislek o njihovih lastnih napakah ter o napakah njihovih sošolcev.

\section{LITERATURA}

AŽMAN, Branko (2004) Nekateri ključni dejavniki procesa učenja slovnice. Vestnik XXXVIII, 7-30

BARTRAM, Mark in WALTON, Richard (1994) Correction: a positive approach to language mistakes. Hove: Language Teaching Publications

BISAILLON, Jocelyne (1992) La révision de textes: un processus à enseigner pour l'amélioration de production écrites. La revue canadienne des langues vivantes 2 , 276-291.

CALVE, Pierre (1992) Corriger ou ne pas corriger, là n'est pas la question. Revue canadienne des langues vivantes 48, 35-49.

CALVET, Louis-Jean (1988) Autour de la norme. Diagonales 8, 22-37.

CORDER, Stephen Pit (1982) Error analysis and interlanguage. Oxford: Oxford University Press

DEBYSER, Francis et al (1970) la linguistique contrastive et les interférences. Langue française 8, 31-35.

DROUARD, Françoise (2009) Enseigner intelligemment l'orthographe. Paris, Delagrave Edition.

ELLIS, Rod (1994) Second Language Acquisition and Language Pedagogy. Oxford, University Press

GRUAZ, Claude (1995) Eléments de morphologie: le système et la norme orthographiques. Liaisons HESO 25,26, 39-53

JAMES, Carl (1998) Errors in language learning and use: exploring error analysis London; New York : Longman

JOHNSON, Keith (2001) An introduction to foreign language learning and teaching. London: Longman

LAH, Meta (2001) Vrednotenje razumevanja tujejezičnega pisnega besedila (Branje pri pouku francoščine v srednji šoli), Magistrska naloga, Univerza v Ljubljani

LAMY, André (1976) La pédagogie de la faute ou de l'acceptabilité. Etudes de linguistique appliquée 22, 118-127. 
LEVENSTON, E.A. (1978) Error analasys of free composition: the theory and the practice. Indian Journal of Applied Linguistics 1, 1-11

PIRIH SVETINA, Nataša (2003) Napaka v ogledalu procesa učenja tujega jezika. Jezik in slovstvo 48, 17-26

PORQUIER, Rémi (1995) Trajectoires d'apprentissages de langues: diversité et multiciplité des parcours. Etudes de linguistique appliquée 98, 92-102.

RIEGEL, Martin e tal (2002) Grammaire méthodique du français. Paris: Presses universitaires de France

SEMKE, Harriet, D. (1984) The effects of the red pen. Foreign Language Annals 17, 22-33.

SOKOLOV, Cvetka (2000) Učenje na tujih vzorih in napakah. Vestnik XXXIV, 493-497

YAGUELLO, Marina (1991) En écoutant parler la langue. Paris, Seuil.

\section{POVZETEK}

\section{Popravljanje in odpravljanje napak v procesu usvajanja tujega jezika}

Pričujoči članek obravnava odnos učiteljev in jezikoslovcev do napak učencev v procesu usvajanja tujega jezika. V zadnjem času se je odklonilni odnos spremenil, podrobna analiza napak in njihovo razvrščanje pa sta privedla do tega, da so napake postale dragocen pripomoček za delo v razredu. Ta novi pristop do napak spodbuja učence k razmisleku o njihovih napakah in o delovanju jezikovnega sistema, ki ga želijo usvojiti. Učitelj, ki si prizadeva izboljšati jezikovno kompetenco svojih učencev, mora imeti široko teoretično znanje in dobro mero potrpežljivosti, predvsem pa mora znati izbrati najugodnejši trenutek in najboljši način za obravnavanje določene napake. To slednje je dolg proces, ki zahteva dejavno sodelovanje tako s strani učitelja kot učenca.

Ključne besede: napake, popravljanje, analiza napak

\section{RÉSUMÉ}

\section{Le traitement et la correction des erreurs dans le processus de l'apprentissage d'une langue étrangère}

Le présent article traite du rapport qu'ont les enseignants et les linguistes face aux erreurs des apprenants dans le processus de l'apprentissage d'une langue étrangère. Ainsi, dans une classe de langue, l'erreur trouve un nouveau statut, elle représente un précieux outil de travail grâce à une analyse minutieuse et à la classification des erreurs des apprenants. De même, cette nouvelle approche incite les aprenants à se pencher sur leurs propres erreurs tout en saisissant le fonctionnement du systeme linguistique de la langue qu'ils voudraient maîtriser. Le professeur qui s'attache à améliorer la compétence langagière de ses apprenants doit avoir de larges connaissances théoriques et pratiques et doit être muni d'une bonne dose de patience. Il doit notamment savoir choisir le meilleur moment et la meilleure façon pour traiter une erreur donnée. Le traitement de l'ereur est donc un long processus qui demande une participation active aussi bien de la part du professeur que de celle de l'apprenant. 


\begin{abstract}
Dealing with errors in the process of foreign language acquisition

This article considers the attitude of teachers and linguistis towards the students' errors during the process of foreign language acquisition. The unfavourable attitude has changed, so that analysis of errors and its categorisation have turned errors into a valuable device used in the classroom. This new approach to errors encourages the students to think about their errors and the functioning of the language system which they want to acquire. The teacher who tries to improve the students' language competence, has to have good theoretical knowledge and a great deal of patience, but above all has to be able to choose the most appropriate moment and way to treat the error, which is a very long process demanding a very active collaboration between a teacher and a student.
\end{abstract}

Key words: errors, treating errors, error analysis 